\title{
Cardiovascular disease in women
}

\author{
Damijan Šimičić ${ }^{1 *}$, Dejan Štrbac ${ }^{1}$, Alen Ružić ${ }^{2}$ \\ ${ }^{1}$ University of Rijeka School of Medicine, Rijeka, Croatia \\ ${ }^{2}$ University of Rijeka School of Medicine, University Hospital Centre Rijeka, Rijeka, Croatia
}

Cardiovascular disease (CVD) is the most common cause of death and disability in female patients with a steady increase in incidence. Available data suggest that there are significant differences between men and women in CVD epidemiology, diagnostic procedures, prognosis and effects of the treatment. A series of open questions reflect differences in CVD risk that are defined by different hormonal status throughout the life in men and women. Different sensitivity and specificity for a number of diagnostic cardiovascular tests is described for female patients, as well as the uneven response to the therapy in the practically same clinical

Received: $20^{\text {th }}$ Apr 2014

*Address for correspondence: Medicinski fakultet Sveučilišta u Rijeci, B. Branchetta 20, HR-51000 Rijeka, Croatia

Phone: +385-91-8824-969

E-mail: damijan1989@ hotmail.com circumstances. Also, the mortality from CVD is higher in women than in men. It might be explained by a higher median age and a higher degree of comorbidity. It is still not possible to give precise answers to a number of open questions in this field which is mostly due to the fact that women are generally underrepresented in randomized controlled trials. A similar relationship can be found in the studies that examine the diagnostic and/or therapeutic cardiovascular procedures. Nevertheless, we should be aware that women are more often prescribed nitrates, calcium channel blockers, diuretics and sedatives, but in a minor percentage they receive beta-blockers, statins and aspirin than men. In this review, we have analyzed the available scientific sources on cardiovascular morbidity in women with a special emphasis on open issues and priorities for the future studies.

KEYWORDS: women, cardiovascular disease, coronary artery disease.

CITATION: Cardiol Croat. 2014;9(5-6):225.

\section{Literature}

1. Eaker ED, Chesebro JH, Sacks FM, Wenger NK, Whisnant JP, Winston M. Cardiovascular disease in women. Circulation. 1993_88:1999-2009.

2. Mosca L, Manson JE, Sutherland SE, Langer RD, Manolio T, Barrett-Connor E. Cardiovascular disease in women: a statement for healthcare professionals from the American Heart Association. Writing Group. Circulation 1997;96:2468-82.

3. Cooper R, Cutler J, Desvigne-Nickens P, et al. Trends and disparities in coronary heart disease. Circulation. 2000;102:3137-47. 